A Model of Gender Prejudice, Power, and Discrimination: How Hierarchy-Enhancing Factors Predominate over Hierarchy-Attenuating Factors

\author{
Emmanuelle P. Kleinlogel
}

Université Clermont Auvergne, Université Blaise Pascal, Laboratoire de Psychologie Sociale et Cognitive, BP 10448, F-63000 Clermont-Ferrand, France CNRS, UMR 6024, LAPSCO, F-63037 Clermont-Ferrand, France emmanuelle.kleinlogel@univ-bpclermont.fr

\title{
Joerg Dietz
}

University of Lausanne, Faculty of Business and Economics, Department of Organizational Behavior, CH-1015 Lausanne-Dorigny, Switzerland jorg.dietz@unil.ch 


\begin{abstract}
Gender inequalities remain an issue in our society and particularly in the workplace. Several factors can explain this gender difference in top-level managerial positions such as career ambitions but also biases against women. In our chapter, we propose a model explaining why gender inequalities and particularly discrimination against women is still present in our societies despite social norms and existing legislation on gender equality. To this purpose, we review research on discrimination through two different approaches, (a) a prejudice approach through the justification-suppression model developed by Crandall and Eshleman (2003) and (b) a power approach through the social dominance theory (Pratto, Sidanius, Stallworth, \& Malle, 1994; Sidanius \& Pratto, 1999). In our work, we integrate these two approaches and propose a model of gender prejudice, power, and discrimination. The integration of these two approaches contributes to a better understanding of how discrimination against women is formed and maintained over time.
\end{abstract}


Gender inequalities remain an issue in our society and particularly in the workplace (Morrison \& von Glinow, 1990; Pratto, Sidanius, \& Levin, 2006). For instance, whereas women represent almost half of the workforce, they occupy less than $5 \%$ of executive manager positions in public listed companies (International Labour Organization, 2015). Several factors can explain this gender difference in top-level managerial positions such as career ambitions but also biases against women (Morrison \& von Glinow, 1990).

In this chapter, we propose a model explaining why gender inequalities and particularly workplace discrimination against women is still present in our societies despite social norms and existing legislation on gender equality (Treviño \& Nelson, 2003). To this purpose, we review research on discrimination through two different approaches, that is (a) prejudice through the justification-suppression model developed by Crandall and Eshleman (2003) and (b) power through the social dominance theory (Pratto, Sidanius, Stallworth, \& Malle, 1994; Sidanius \& Pratto, 1999). We then propose a model integrating these two approaches, namely the model of gender prejudice, power, and discrimination. The integration of these two approaches contributes to a better understanding of how discrimination against women is formed and maintained over time. Indeed, whereas the first approach helps to understand processes through which prejudice is expressed, the second helps to understand the sustainable dominance of men over women through a multi-level approach and a power and behaviour asymmetry.

The chapter is organized as follows. In the two first sections, we introduce the theoretical background related to the two approaches, namely the justification-suppression model (Crandall \& Eshleman, 2003) and the social dominance theory (Sidanius \& Pratto, 1999). We then present our model and explain how these approaches are complementary. Finally, before concluding we discuss the implications of our model.

\section{Psychology of Prejudice and Discrimination}

\section{Definition of Prejudice and Discrimination}

Prejudice can be defined as "a negative evaluation of a social group or a negative evaluation of an individual that is significantly based on the individual's group membership" (Crandall \& 
Eshleman, 2003, p. 414; see also Brigham, 1971; Paluck \& Green, 2009). A social group refers for instance to age, disability, gender, national origin, culture, race, ethnicity, sexual orientation, social class, and religion. In this chapter, we adopt the view of Crandall and Eshleman (2003) who presented prejudice as a motivational variable such that when individuals are confronted with a target of their prejudice, they are motivated to express them. However, if this motivation cannot be fulfilled, dissatisfaction might result. The behavioural expression of prejudice leads to discriminatory behaviour.

Discrimination can be defined as unfair treatment of the members of a group (e.g., social class and gender) due to their membership in this group (Dietz, Kleinlogel, \& Chui, 2012). In the workplace context, discrimination occurs when employees are treated differently based on factors not related to their qualifications such as their ethnicity or gender (Pratto et al., 2006; Treviño \& Nelson, 2003). However, discrimination does not always occur through a simple expression of prejudice. Instead, it is most often the result of processes, which are a function of social and personal factors. These factors act as a motivational force in favour either of the suppression or the release of prejudice (Crandall \& Eshleman, 2003; Pratto et al., 2006). These factors are presented in the next section.

\section{The Justification-Suppression Model of Prejudice}

Crandall and Eshleman (2003) proposed a model to explain how prejudice is expressed, namely the Justification-Suppression Model (JSM) of the expression and experience of prejudice. The JSM finds its foundation in the two-factor theories of racial prejudice (e.g., Allport, 1954; Gaertner \& Dovidio, 1986; Katz \& Hass, 1988; Rogers \& Prentice-Dunn, 1981). These theories state that individuals are confronted with two competing motivations, (a) prejudice and (b) the motivation to control it. Accordingly and through the JSM, Crandall and Eshleman proposed that individuals face motivational force attempting to either refrain or foster the expression of prejudice, namely suppression factors and justification factors. Whereas suppression factors refrain individuals' prejudice expression, justification factors allow individuals releasing their prejudice without experiencing (or experiencing to a low extent) internal or external sanction (Crandall \& Eshleman, 2003). Suppressors can take several forms such as social norms promoting tolerance, and personal values such as empathy and egalitarianism. Justifiers can be grouped into three categories; those stemming from individual differences (e.g., belief in a just world, Lerner, 1980; right-wing authoritarianism, 
Altemeyer, 1981), those that are situation-specific (e.g., situational ambiguity), and those stemming from intergroup processes (e.g., intergroup contact, Amir, 1976).

Through their model, Crandall and Eshleman (2003) proposed that at the first stage the expression of prejudice is prevented through suppression factors whereas at the second stage it is fostered by the presence of justification factors. They argued that the presence of suppression factors fosters individuals' motivation and need to seek justification factors, which then would allow individuals to express their prejudice. These processes imply that "prejudice itself is usually not directly expressed, but rather is modified and manipulated to meet social and personal goals" (Crandall \& Eshleman, 2003, p. 416).

The JSM contributes to the literature on discrimination by explaining how prejudice can still be expressed through motivational forces despite the presence of counterbalancing forces (i.e., suppression factors). However, this model does not provide theoretical explanations for why discrimination is maintained over time. In the next sections, we briefly review social dominance theory (Sidanius \& Pratto, 1999) and explain how this theory is complementary to the model developed by Crandall and Eshleman (2003). We then present the model of gender prejudice, power, and discrimination in which we integrate social dominance theory in the JSM and apply it to discrimination against women.

\section{Social Dominance Theory}

Social Dominance Theory (SDT) was developed to explain how discrimination through group-based inequalities is formed and maintained by focusing on the notion of power (Sidanius, Pratto, van Laar, \& Levin, 2004; Pratto et al., 2006). Social dominance can be defined as the desire for individuals to live in a hierarchically group-based structured society (Pratto et al., 1994). According to this theory, each society should be organized based on three distinct systems to be able to reach a stable economic level, namely an age system, a gender system, and an arbitrary-set system (i.e., a system in which groups are organized on an arbitrary basis such as nationality, origin, and religion). In each of these systems, members of dominant groups have disproportionate social power over the members of subordinate groups (O’Brien \& Dietz, 2011; Pratto et al., 2006). Social power refers to "the ability to impose one's will on others, despite resistance" as opposed to social status which refers to "the amount of prestige one possesses along some evaluative dimension" (Sidanius et al., 2004, p. 
865). For instance, adults, men, and locals have more social power than children, women, and immigrants. As a consequence, this trimorphic structure leads to discrimination through unfair inequalities between members of dominant groups and subordinate groups.

In this approach, discrimination is conceptualized as a means of forming and maintaining a group-based social hierarchy (Sidanius et al., 2004) and prejudice is conceptualized as partly motivated by social dominance in terms of individuals' desire to acquire power for their own group at the detriment of the other groups (McDonald, Navarette, \& Sidanius, 2011). Central to SDT is the notion of legitimizing myths. Legitimizing myths are "attitudes, values, beliefs, stereotypes, and ideologies that provide moral and intellectual justification for the social practices that distribute social value within the social system" (Sidanius \& Pratto, 1999, p. 45). The theory distinguishes between two types of legitimizing myths; those enhancing group-based inequalities and those attenuating group-based inequalities, namely HierarchyEnhancing (HE) legitimizing myths and Hierarchy-Attenuating (HA) legitimizing myths. HE legitimizing myths provide a rational explanation for group-based inequalities and justify the practices that maintain them (e.g., stereotypes, just world beliefs) whereas HA legitimizing myths tend to reduce group dominance by "delegitimizing inequality or the practices that sustain it, or by suggesting values that contradict hierarchy" (e.g., egalitarian values and democratic political doctrine, Sidanius \& Pratto, 1999, p. 104; see also Pratto et al., 2006).

In addition to legitimizing myths, at the upper level in societies SDT distinguishes between HE and HA institutions. HE institutions are institutions which "promote and sustain inequality by allocating disproportionately more positive social value or less negative social value to dominant groups than to subordinate groups" whereas HA institutions are institutions which "disproportionately aid members of subordinate social groups (e.g., the poor, ethnic and religious minorities) and attempt to open access to resources otherwise restricted to dominants (e.g., public services)" (Pratto et al., 2006, pp. 276-277).

\section{A Model of Gender Prejudice, Power, and Discrimination}

In our research, we draw on the JSM and extend it by integrating SDT. Figure 9.1 is a graphical depiction of our model of gender prejudice, power, and discrimination. Integrating SDT in the JSM allows for a more complete understanding of how gender inequalities and particularly workplace discrimination is formed and maintained over time for two main 
reasons. First, the JSM and SDT share some common aspects. Both views argue for discrimination as a function of prejudice and other motivational forces conceptualized as justification and suppression factors through the JSM and as HE and HA legitimizing myths through SDT. However, SDT is complementary to the JSM through its multi-level approach by helping to understand how discrimination is formed and maintained at and across different levels of the society.

Second, whereas the JSM and SDT share some common aspects, they contribute uniquely to understand processes of discrimination and its maintenance. On one hand, as described previously, the JSM contributes to a better understanding of the process through which prejudice is expressed. On the other hand, SDT contributes to the understanding of discrimination through power and behavioural asymmetry. In the following sections, we first introduce our model and then present the uniqueness of SDT in more detail and how it helps to understand gender-based inequalities through our model.

\section{<FIGURE 9.1 HERE>}

\section{Presentation of the Model}

The model we propose is an adaptation of the JSM developed by Crandall and Eshleman (2003) for discrimination against women, and in which we integrate elements of SDT (Sidanius \& Pratto, 1999) (see Figure 9.1). Our work implies three main changes in the initial JSM. First, we focus on prejudice related to gender and particularly prejudice targeting women. Second, we focus on gender inequalities as an outcome of gender prejudice. Finally, we rename suppression and justification factors as HA and HE factors. This label change aims at integrating the notion of power and behavioural asymmetry unique to SDT through the term hierarchy.

Our model is thus composed of four elements, namely gender prejudice, gender inequalities, HA and HE factors. However, contrary to Crandall and Eshleman (2003) who drew a figure to illustrate how these four elements work together, our model is a depiction of a structural equation model (see Figure 9.1). First, gender prejudice is represented as a predictor of gender inequalities. Second, HA and HE factors are represented as moderators in the relationship between gender prejudice and gender inequalities. HA factors are conceptualized as factors 
weakening this relationship whereas HE factors are conceptualized as factors strengthening it. In line with the JSM, we represent HE factors on the right side of HA factors to emphasize the theoretical argument that HE factors occur after HA factors. Indeed, according to Crandall and Eshleman the presence of prejudice and HA factors calls for the need to seek for HE factors to be able to express the prejudice individuals harbour and thus to engage in discriminatory behaviour against women.

The integration of SDT in our model has two implications. These implications are related to the uniqueness of SDT in helping to understand group-based inequalities, namely its multilevel approach, and its notion of power and behavioural asymmetry. First, it implies adopting a multi-level approach of HA and HE factors in our model. Second, this integration adds a theoretical explanation to the model on how gender inequalities are formed and sustained over time through a consensual acceptance of these gender inequalities by both gender groups. In the following sections, we present elements of SDT that we integrate in our model and explain in more detail the implications of this integration on our understanding of discrimination against women.

\section{Multi-level Approach}

Contrary to the JSM, SDT has a multi-level approach of factors that either attenuate or enhance discrimination and argues for the coordination of these factors across the different levels contributing to forming and maintaining group-based hierarchy (Pratto et al., 2006). SDT distinguishes between three distinct levels, the individual level, the group level, and the institutional level, respectively. At the individual level, HA and HE factors are composed of individual differences reducing (e.g., egalitarian values) or providing the rationale for the expression of prejudice (e.g., stereotypes). At the group level, they are mainly composed of processes justifying prejudice (e.g., stereotypes threat). Finally, at the institutional level HA and HE factors are composed of institutions acting either in favour of equality of treatment between groups (e.g., welfare organizations) or in favour of group-based inequalities (e.g., criminal justice systems).

We propose to add this multi-level approach to our model. To this purpose, we classify HA and HE factors into the three levels defined by SDT. Table 9.1 reports this classification in which we combine HA and HE factors listed by Crandall and Eshleman (2003) and by Pratto 
et al. (2006) (see for a detailed description of these factors, Crandall \& Eshleman, 2003; Pratto et al., 2006). As displayed by Table 9.1, some factors are common to the two categories of HA and HE factors such as religious organizations and political value systems at the institutional level because these factors can either weaken or foster the expression of gender prejudice depending on their content. For instance, some religious organizations can promote tolerance whereas others can disapprove and thus sanction certain types of behaviours such as single mothers (Crandall \& Eshleman, 2003; Jackson \& Esses, 1997). At the individual level, social status beliefs and values include beliefs supporting the status quo and social hierarchy such as Protestant work ethic (Katz \& Hass, 1988), social dominance orientation (Pratto et al., 1994), and sexism (Glick \& Fiske, 1996). Attributional and covering processes refer to factors allowing individuals to blame the targets of prejudice for their fate (e.g., attributional scapegoating) or to justify the expression of their prejudice through seemingly legitimate explanations (e.g., situational ambiguity) (see Crandall \& Eshleman, 2003). Apart from its multi-level approach, the uniqueness of SDT in explaining how discrimination is formed and maintained resides in its notion of power and behavioural asymmetry.

\section{<TABLE 9.1 HERE>}

\section{Power Asymmetry}

SDT argues for an asymmetry in power between HE and HA institutions, in which HA institutions are disadvantaged leading to the maintenance of group-based hierarchy (Pratto et al., 2006). According to SDT, HE institutions have more power than HA institutions because whereas the former usually allocate both positive social value to dominant groups and negative social value to subordinate groups, the latter tend to only allocate positive value to subordinate groups. As a result, the net effect of these two types of institutions favours dominant groups over subordinate groups which then contribute to maintain group-based inequalities.

For instance, due to their gender role women are penalized when they take a maternity leave, that is, women applicants are less likely to be hired than men applicants because they have less professional experience (O’Brien \& Dietz, 2011; Treviño \& Nelson, 2003). This institutional gender discrimination provides both a negative social value to women and a positive social value to men who have increased chances of being hired. Regarding HA 
institutions such as organizations helping women to find a job after a maternity leave, they allocate only a positive social value to women. As a consequence, men keep their advantage over women. The maintenance of these gender inequalities is also due to the power asymmetry between the two gender groups. Indeed, it is easier for men, as dominant group members and occupying top-level positions in society, to protect their social dominance by maintaining gender inequalities than for women, as subordinate group members, to change their well-accepted gender role. For instance, it is easy for a male human resources manager to favour members of his gender group by hiring only male applicants into managerial positions as compared to female applicants seeking access to such positions.

\section{Behavioural Asymmetry}

Apart from the power asymmetry, SDT argues for a behavioural asymmetry between members of different groups such that dominant group members and subordinate group members collaborate in an effort to maintain a group-based hierarchy. SDT distinguishes between three different types of behavioural asymmetry, namely the asymmetrical ingroup bias, self-debilitating behaviours among subordinates, and ideological asymmetry. First, through the asymmetrical ingroup bias, the theory states that ingroup favouritism differs between members of distinct groups such that in a stable group-based system individuals tend to favour dominant groups by endorsing HE legitimizing myths and by accepting group-based hierarchy over HA legitimizing myths independently of their group membership. As a result, dominant groups engage in ingroup favouritism whereas subordinate groups do so to a lesser extent or contribute to their oppression by engaging in outgroup favouritism (O'Brien \& Dietz, 2011; Pratto et al., 2006; Sidanius \& Pratto, 1999; Sidanius et al., 2004).

Second, self-debilitating behaviours refer to self-destructive and self-damaging behaviours (e.g., stereotype threat leading women to poorly perform in male-typed task, Spencer, Steel, \& Quinn, 1999) perpetuated by members of subordinate groups (O’Brien \& Dietz, 2011; Pratto et al., 2006; Sidanius \& Pratto, 1999; Sidanius et al., 2004). Self-debilitation is the result of self-fulfilling prophecies among subordinate group members stemming from HE legitimizing myths. Finally, the notion of ideological asymmetry refers to the greater compatibility of HE legitimizing myths with dominant group members than with subordinate group members, thus favouring the dominance of the former over the latter (Pratto et al., 2006). For instance, a successful leader tends to be perceived as a person with agentic attributes such as competitive 
and ambitious (Eagly \& Karau, 2002). This view contributes to the underrepresentation of women in leadership positions given that women tend to be perceived as having less agentic attributes than men and more communal attributes such as helpful and sensitive.

This asymmetry in behaviour between members of different groups provides additional explanations for gender discrimination by arguing (a) for a consensual preference for the dominant group members, men, and (b) for a consensual acceptance of gender-based hierarchy. As a result, both men and women collaborate to achieve and maintain gender inequalities thus rendering HA factors powerless. As an example, legislations on gender equality are created to reduce gender discrimination and particularly to reduce the treatment difference between men and women in organizations (Treviño \& Nelson, 2003). Despite these legislations, most top-management positions are occupied by men (International Labour Organization, 2015). One of the HE legitimizing myths providing the rationale for this gender segregation is the gender role stereotype in which men are perceived as having "breadwinner and higher status roles" whereas women are perceived as having "homemaker and lower status roles" (Eagly \& Karau, 2002, p. 574). Men are thus favoured to occupy managerial and particularly leadership positions as opposed to women who are favoured for jobs such as child care. This myth tends to be endorsed by both men and women and has become the norm (Dennerlein, Kleinlogel, Dietz, \& Gabarrot, 2013; Eagly, 1987; Eagly \& Karau, 2002).

\section{Maintenance of Gender Inequalities through a Self-Reinforcing Spiral}

The integration of SDT in the JSM allows for a better understanding of gender inequalities and its maintenance for two reasons. First, through a multi-level approach it allows for a more complete picture of attenuating and enhancing factors of gender inequalities by including the institutional level, which was missing in the JSM. Second, the multi-level approach allows an understanding of the maintenance of gender inequalities by connecting factors at different levels. Indeed and according to SDT, factors at the institutional level, group level, and individual level contribute interactively to the maintenance of gender inequalities forming a self-reinforcing spiral. For instance, at the individual level gender stereotypes contribute to the expression of prejudice, but also contribute to discriminatory group-level processes, such as stereotype threat, and institution-level discrimination, such as female under-representation in top-level positions. At the same time, at the institutional level this gender segregation reinforces stereotypes at the individual level as well as at the group level through self- 
fulfilling prophecies. As a result, gender inequalities are maintained by the interaction of $\mathrm{HE}$ factors at different levels in society. However, this self-reinforcing spiral would not exist without the notion of power and behavioural asymmetry.

Indeed, the presence of HA factors should counteract the effect of HE factors leading to a zero-sum game. However, we observe a disproportionate allocation of power to HE factors as compared to HA factors leading HA factors to be powerless when confronted with HE factors. In addition, this effect is strengthened by a power difference and a behavioural asymmetry between groups. The disproportionate allocation of power to dominant group members (i.e., men) makes subordinate group members (i.e., women) defenceless when faced with inequalities and the behavioural asymmetry acts in support of these inequalities through which both groups favour the dominant group. As a consequence, HE factors at each level of society tend to be stable which then allow the spiral to be continuously self-reinforced and gender inequalities to remain over time.

\section{Discussion}

In this chapter, we propose a model explaining how discrimination against women is achieved and maintained over time, namely the model of gender prejudice, power, and discrimination. We draw on two complementary approaches, namely prejudice and power. First, we draw on the work by Crandall and Eshleman (2003) and particularly on the justification-suppression model of the expression and experience of prejudice to explain how gender prejudice is expressed leading to gender inequalities through discrimination against women. Second, we draw on social dominance theory to explain how these gender inequalities are maintained over time (Sidanius \& Pratto, 1999). Our model is thus an adaptation to discrimination against women of the justification-suppression model integrating elements of social dominance theory (i.e., its multi-level approach and its notion of power and behavioural asymmetry).

\section{Theoretical contributions}

The integration of these two approaches theoretically contributes to a better understanding of gender inequalities by providing a more complete picture of how discrimination against women is formed and maintained. These two approaches of discrimination share common aspects because they both argue for a "win-lose game" between factors enhancing and 
attenuating group-based inequalities. However, the arguments of these two approaches are unique because they focus on two distinct explanations, the powerful effect of prejudice, and power and behavioural asymmetry, respectively. On one hand, through their model Crandall and Eshleman (2003) argue that individuals are motivated to express their prejudice while at the same time, they are also motivated to refrain from doing so due to situational and personal factors (e.g., political value systems, empathetic feeling). These two motivations are conflicting, which leads to "ambivalent emotions, behavioural instability, and cognitive inconsistency" among individuals (Crandall \& Eshleman, 2003, p. 415).

However, whereas situational and personal factors prevent prejudice expression, they also create the need for individuals to seek justifiers. As a result, the presence of justification factors leads individuals to express their prejudice and thus to engage in discriminatory behaviour against women. On the other hand, the social dominance theory argues for a power and behavioural asymmetry in which both members of dominant (i.e., men) and subordinate (i.e., women) groups contribute to the maintenance of gender inequalities through genderbased hierarchy acceptance (Sidanius \& Pratto, 1999). Through its multi-level approach, this theory also argues that this power and behavioural asymmetry is strengthened by the coordination of hierarchy-enhancing factors across the different levels of society (i.e., individual, group, and institutional level).

\section{Practical Implementations}

Our model allows reflecting on how gender inequalities can be reduced. According to our model, gender inequalities are a function of gender prejudice, HA factors, and HE factors. We propose to focus on the processes by which prejudice is expressed to discover potential interventions to reduce gender inequalities. Particularly, we focus on the interactive effects of HE factors at different levels in society. Potential interventions would be to weaken the selfreinforcing spiral by breaking the effect of one of its components. Whereas it seems difficult to act at the individual and group levels in which processes are mostly influenced by prejudice, we suggest a top-down approach by acting at the institutional level.

Potential interventions would include introducing HA factors within HE institutions such as new legislation targeting institutional selection processes. As a concrete example, legislation introducing gender quotas within firms and reflecting the actual population might be one 
possible way to remedy the situation. For instance, if women represent $40 \%$ of the topqualified workforce, firm top-management board composition should reflect this percentage. In the short term, such intervention would allow to allocate both a positive social value to women by favouring the employment of female applicants in top-level positions and a negative social value to men by hiring fewer male applicants in these positions. In the long term, this intervention would have an effect on HE factors at the individual and group levels by, for instance, changing gender role stereotypes towards a less biased view of gender role in societies.

\section{Future Research}

To conclude, we suggest that future research should use our model to empirically investigate the conflicting effect of gender prejudice, hierarchy-attenuating, and hierarchy-enhancing factors on individuals' propensity to engage in discriminatory behaviour against women. For instance, it would be interesting to study the effect of prejudice, hierarchy-attenuating factors, and hierarchy-enhancing factors on employment discrimination against women. As a concrete example, one might test the interactive effect of gender prejudice, organizational norms promoting gender equality treatment, and situational ambiguity on individuals' propensity to hire female applicants for top-level positions.

We expect prejudiced individuals to be less likely to hire female applicants for top-level positions in cases of situational ambiguity (e.g., male and female applicants equally qualified for the positions) than in the absence of situational ambiguity (e.g., female applicants more qualified than male applicants). We also expect gender equality norms to moderate the relationship between prejudice, situational ambiguity, and individuals' employment decisions. For instance, we expect that when there is no situational ambiguity prejudiced individuals are less likely to hire female applicants for top-level positions in absence of equality treatment norms than in presence of such norms. Such empirical evidence would allow for a better understanding of processes leading to discrimination against women and thus maintaining gender inequalities, which then would ultimately allow reflection on how to counteract hierarchy-enhancing factors. 


\section{References}

Allport, G. H. (1954). The nature of prejudice. Cambridge, MA: Addison-Wesley.

Amir, Y. (1976). The role of intergroup contact in change of prejudice and ethnic relations. In P. A. Katz (Ed.), Towards the elimination of racism (pp. 245-308). New York, NY: Pergamon.

Altemeyer, R. (1981). Right-wing authoritarianism. Winnipeg: University of Manitoba Press.

Brigham, J. C. (1971). Ethnic stereotypes. Psychological Bulletin, 76, 15-38. doi: $10.1037 / \mathrm{h} 0031446$

Crandall, C. S., \& Eshleman, A. (2003). A justification-suppression model of the expression and experience of prejudice. Psychological Bulletin, 129, 414-446. doi: 10.1037/00332909.129.3.414

Dennerlein, T., Kleinlogel, E. P., Dietz, J., \& Gabarrot, F. (2013, April). Gender ingroup prototypicality and manager prototypes. Paper presented at the $28^{\text {th }}$ Annual Conference of the Society for Industrial and Organizational Psychology, Houston, Texas, USA.

Dietz, J., Kleinlogel, E. P., \& Chui, C. W. S. (2012). Research on intergroup conflict: Implications for diversity management. In G. K. Stahl, I. Björkman, \& S. Morris (Ed.), Handbook of research in international human resource management (pp. 253-270). Cheltenham, UK: Edward Elgar Publications.

Eagly, A. H. (1987). Sex differences in social behavior: A social-role interpretation. Hillsdale, NJ: Erlbaum.

Eagly, A. H., \& Karau, S. J. (2002). Role congruity theory of prejudice toward female leaders. Psychological Review, 109, 573-598. doi: 10.1037//0033-295X.109.3.573

International Labour Organization (2015). Women in business and management: Gaining momentum. Retrieved from http://www.ilo.org/global/publications/ilobookstore/order-online/books/WCMS_316450/lang--ja/index.htm

Gaertner, S. L., \& Dovidio, J. F. (1986). The aversive form of racism. In J. F. Dovidio \& S. L. Gaertner (Eds.), Prejudice, discrimination, and racism (pp. 61-89). New York, NY: Academic Press.

Glick, P., \& Fiske, S. T. (1996). The Ambivalent Sexism Inventory: Differentiating hostile and benevolent sexism. Journal of Personality and Social Psychology, 70, 491-512. doi : $10.1037 / 0022-3514.70 .3 .491$ 
Jackson, L. M., \& Esses, V. M. (1997). Of scripture and ascription: The relation between religious fundamentalism and intergroup helping. Personality and Social Psychology Bulletin, 23, 893-906. doi: 10.1177/0146167297238009

Katz, I., \& Hass, R. G. (1988). Racial ambivalence and American value conflict: Correlational and priming studies of dual cognitive structures. Journal of Personality and Social Psychology, 55, 893-905. doi: 10.1037/0022-3514.55.6.893

Lerner, M. J. (1980). Belief in a just world: A fundamental delusion. New York, NY: Plenum Press.

McDonald, M. M., Navarette, C. D., \& Sidanius, J. (2011). Developing a theory of gendered prejudice: An evolutionary and social dominance perspective. In R. M. Kramer, G. J. Leonardelli, \& R. W. Livingston (Ed.), Social cognition, social identity, and intergroup relations: A festschrift in honor of Marilynn B. Brewer (pp. 189-220). London: Psychology Press.

Morrison, A. M., \& von Glinow, M. A. (1990). Women and minorities in management. American Psychologist, 45, 200-208. doi: 10.1037/0003-066X.45.2.200

O'Brien, J., \& Dietz, J. (2011). Maintaining but also changing hierarchies: What social dominance theory has to say. In J. L. Pearce (Ed.), Status in management and organizations (pp. 55-84). Cambridge: Cambridge University Press.

Paluck, E. L., \& Green, D. P. (2009). Prejudices reduction: What works? A review and assessment of research and practice. Annual Review of Psychology, 60, 339-367. doi: 10.1146/annurev.psych.60.110707.163607

Pratto, F., Sidanius, J., \& Levin, S. (2006). Social dominance theory and the dynamics of intergroup relations: Taking stock and looking forward. European Review of Social Psychology, 17, 271-320.doi: 10.1080/10463280601055772

Pratto, F., Sidanius, J., Stallworth, L. M., \& Malle, B. F. (1994). Social dominance orientation: A personality variable predicting social and political attitudes. Journal of Personality and Social Psychology, 67, 741-763. doi: 10.1037/0022-3514.67.4.741

Rogers, R. W., \& Prentice-Dunn, S. (1981). Deindividuation and anger-mediated interracial aggression: Unmasking regressive racism. Journal of Personality and Social Psychology, 41, 63-73. doi: 10.1037/0022-3514.41.1.63

Sidanius, J., \& Pratto, F. (1999). Social dominance: An intergroup theory of social hierarchy and oppression. New York, NY: Cambridge University Press. 
Sidanius, J., Pratto, F., van Laar, C., \& Levin, S. (2004). Social dominance theory: Its agenda and method. Political Psychology, 25, 845-880. doi: 10.1111/j.14679221.2004.00401.X

Spencer, S. J., Steele, C. M., \& Quinn, D. M. (1999). Stereotype threat and women's math performance. Journal of Experimental Social Psychology, 35, 4-28. doi : 10.1006/jesp.1998.1373

Treviño, L. K., \& Nelson, K. A. (2003). Managing business ethics: Straight talk about how to do it right ( $3^{\text {rd }}$ Ed.). New York, NY: Wiley. 